\title{
CORRESPONDENCE
}

\section{Dioxin, an emotive word}

SIR, - The tragic murder of the production director of the trichlorphenol plant in Séveso demonstrates most dramatically that "dioxin" has joined a select group of words including "cancer" "nuclear" and "fluoride" which inspire fear and trigger emotions that require the explanations of psychologists not a chemist.

The ease with which traditional standards of rigour in proof can be abandoned when discussing toxicity should be a warning to all serious scientists. The article by David Dickson (31 January, page 418) can do nothing but reinforce the almost mediaeval atmosphere of mystic suspicion which seems to have enveloped this subject.

Pentachlorophenol is probably not one of the most widespread pesticidal chemicals in domestic use in the United Kingdom, other chlorophenols used in disinfectants could perhaps claim that honour, but it is quite widely used as a wood preservative and particularly in the United States. It has been used for more than forty years, and long before the present emphasis on worker safety, so that a very large number of workers have been exposed to considerably greater dosages than any relevant to the "cases" quoted in the article. There is no suggestion that the handling of pentachlorophenol-based wood preservatives, nor even pentachlorophenol itself, has been a major health hazard to operatives in the industry.

Surely if a material utilised at extremely low concentrations in contact with a consumer were to give rise to such dramatic hazards, then we could look for a large number of fatalities or significant debility in workers in the industry. This is simply not the case.

It is important to stress that the most toxic dioxin - tetrachlorodibenz-p-dioxin, has never been found in industrial pentachlorophenol (of modern manufacture) and the accuracy of analysis is now at a confidence level of one part in ten million.

Octachlorodibenz-p-dioxin, which is a known contaminant, is less toxic than pentachlorophenol itself. To claim that little is known of the physical and chemical toxicological properties of other dioxins is unfair, and perhaps the interested reader should refer to "Pentachlorophenol Chemistry.

Pharmacology and Environmental

Toxicology", editor K. Tanga Rao, "Chlordioxins - Origins and Fate" by Ethyl H. Blair, and "Dioxin - Toxicological and Chemical Aspects", edited by Flamino Cattabeni, Aldo Cavaliaro, Giovanni Gallis. The hexachlordioxins, which are found in technical pentachlorophenol of the quality now available in Europe, are at a level of about five parts per million, and the most toxic isomers are at proportionately lower levels. Their chronic toxicity is well established and it would be necessary to take more than the lethal dose of technical pentachlorophenol regularly in order to run the risk of future development of cancer. In effect the acute toxicity of pentachlorophenol protects against long term hazard.

The approach of certain environmentalists and American attorneys seems to centre on contaminants, even if present in extremely small quantities overlooking the accepted acute toxicity of the main ingredients. Furthermore they seem to believe that pentachlorophenol is applied in isolation and disregard co-solvents, solvents, carriers, resins, pigments and dyes, all of which form part of preservative formulations, the majority of which will certainly not have been investigated for impurities nor their toxicology determined with anything approaching the thoroughness applied to pentachlorophenol. Nor is any mention made of the potential hazards to man of the organisms which pentachlorophenol controls.

Your readers can be assured that there is no iceberg, the divers have been down these many years and would have found it. Can I plead that we remember that all chemicals are toxic, it is only a matter of determining the dose?

Finally, I revert to my opening remark, can any psychologist offer an explanation of this fear and the profound emotions it releases? Yours faithfully,

J. DAVID

Catomance Ltd, Welwyn Garden City, Hertfordshire, UK.

\section{World energy needs of the future}

SIR, - R.B. Temple, in a letter (7 February, page 520) virtually as long as my (necessarily limited) review of World Energy - Looking Ahead to 2020 (15 November, page 344), says many things I would readily endorse.

It is for the reader to judge whether I was sufficiently critical of the energy strategy proposed by the Conservation Commission of the World Energy Conference. My emphasising, through direct quotation as a form of shorthand, of the Commission's conclusion that their assessment required "doubling nuclear power plant capacity every six years", was indeed meant to signal the reader to the far-fetched numbers this implied and which Dr Temple has calculated. No disagreement here, whatsoever, especially as the latest official UK estimates of new reactor capital costs are nearer $£ 1000 / \mathrm{kW}$, or $£ 1 \times 10^{9}$ for a $1000 \mathrm{MWe}$ plant.

As for my own position in the energy debate, I would suggest an examination of Chapter 5 of World Futures - The Great Debate (ed C. Freeman and M. Jahoda), Martin Robertson, Oxford, 1978 which was reviewed by Lord Ashby in Nature, (November 9, 1978, page 144). I suspect Dr Temple and I would share much common ground.

Yours faithfully, J. H. CHESSHIRF

Science Policy Research Unit, University of Sussex, UK

\section{Nuclear energy and the world economy}

SIR, - R.B. Temple, who wrote a letter in your 7 February issue (page 520) commenting on the problem of feeding world economy with nuclear energy has been trapped in a famous pitfall, which is to assume that the size of a certain machine, in the particular case that of a nuclear reactor, is God given and time invariant.

Now, if we analyse energy systems or transportation, or chemical ones, we find that there exists a very tight link between the size of a plant and that of the market, in most cases the link being that of simple proportionality. So, if one increases electricity consumption by say a factor of 1000 , which happened for example in the US from the beginning of the century to present, the number of power stations stays constant (or more precisely decreased somewhat) because the stations' size grew with the market. There are presently about 3000 electric power stations in the world, of a certain size and connected to grids, and presumably a smaller number will be present in the year 2020. Consequently the number of plants to be constructed every year if we assume a life of 30 years will be 3000:30 or 100 per year at regime, which is not an extraordinary figure if we think it spread over the world. If we choose an energy vector different from electricity to carry around the energy, the number of reactors will depend on the cost of transportation. If we take hydrogen as an example, transportation costs in the proper context are an order of magnitude lower, and this makes generation possible in fewer and larger machines - say 100 for the whole world, with a replacement ratio of 3 per year. Does this still sound too many?

I am not entering into the complex question of financing energy systems development. I am just attracting attention to the fact that final consumers now pay for their energy something in the range of $\$ 1.5 \times 10^{12 / y e a r}$ Yours faithfully,

C. MARCHETT

International Institute for Applied Systems Analysis, Laxenburg, Austria

\section{Fast reactor safety and the fire at Beloyarsk}

SIR, - Vera Rich's piece (31 January, page 420 ) based on a clandestine report of a fire at Beloyarsk in the USSR associates the fire with the fast reactor (BN600), at that site, and implies faults in the safety arrangements for that and, by implication, other fast reactors.

Beloyarsk is the site of two graphite mode rated steam-cooled reactors, which were completed some years ago, and of the fast reactor BN600 which, at the time of the alleged fire, was still at least 12 months short of completion. The assumption that the fire, if any, might have led to the escape of radioactive sodium from the primary circuit of this reactor is, therefore, questionable, to say the least.

BN600 is a pool type reactor in which the core, pumps and primary heat exchangers are submerged in sodium contained in a strong double-skinned reactor tank. There is, therefore, no circuit, in the physical sense, which could 'rupture' and "cause an explosion scattering radioactive material in a

cloud ....". Vera Rich's reference to "the 1957 Kyshtym disaster"' is equally inappropriate in the light of our ignorance of the nature, cause, or extent, of this incident.

It is not clear what implication the reader is meant to draw from the remark that "the fire at the Shevchenko fast breeder ... " was no technically a "nuclear disaster", This topic has previously been ventilated in your columns and information has been supplied which demonstrates both that this fire was no sort of disaster and that no radioactivity was involved since the circuit which leaked was a secondary sodium circuit external to the reactor.

Fast reactor safety is of public importance and, in your columns at least, deserves a more objective treatment than is displayed in Vera Rich's article.

Yours faithfully,

R.D. SMITH

Fast Reactor Development Directorate, United Kingdom Atomic Energy Authority, Risley. UK 